\title{
The engram found? Role of the cerebellum in classical conditioning of nictitating membrane and eyelid responses
}

\author{
DAVID A. McCORMICK, DAVID G. LAVOND, GREGORY A. CLARK, \\ RONALD E. KETTNER, CHRISTINA E. RISING, and RICHARD F. THOMPSON \\ Stanford University, Stanford, California 94305
}

\begin{abstract}
Electrophysiological recording of neural unit activity during paired training trials from the ipsilateral cerebellum in rabbits well trained in short-delay classical conditioning of the nictitating membrane (NM) and eyelid responses showed CS- and UCS-evoked responses and a pattern of increased neural activity that correlates with the learned behavioral response. Large ablations of the ipsilateral cerebellum completely and permanently abolished the conditioned response in well trained animals, as did more localized stereotaxic lesions. These lesions had no effect at all on the unconditioned reflex response. In marked contrast, conditioned responses were easily trained in the eye contralateral to the cerebellar lesion. We suggest that at least a part of the "engram," the essential neuronal plasticity that codes the learned response, may be localized to the cerebellum.
\end{abstract}

The initial goal in the analysis of the "engram," the essential neuronal plasticity that codes learning and memory, is to determine the location of the engram in the brain, if such exists. To date, this has not been done for any instance of associative learning in the mammalian brain. We report here evidence suggesting that the engram for a simple form of associative learning, shortdelay classical conditioning of the nictitating membrane (NM) and eyelid responses in the rabbit, is at least in part localized to the cerebellum. Because this result is of considerable potential importance, we are taking the somewhat unusual step of reporting preliminary results from experiments still in progress.

A number of brain regions are involved even in a "simple" conditioned response (CR). In NM and eyelid conditioning, both the neocortex (Megirian \& Bures, 1970; Papsdorf, Longman, \& Gormezano, 1965) and the hippocampus (Thompson, Berger, Berry, Hoehler, Kettner, \& Weisz, 1980) normally play important roles. In the case of the hippocampus, this is particularly so when greater demands are placed on the memory system, as in trace conditioning or latent inhibition (Solomon \& Moore, 1975; Weisz, Solomon, \& Thompson, Note 1). However, rabbits with all brain tissue above the level of the thalamus removed can learn the short-delay classically conditioned NM response (Enser, Note 2), and decerebrate cats can learn the short-delay classically conditioned eyelid response (Norman, Buchwald, \& Villablanca, 1975). These results suggest that there is an essential neuronal circuit below the level of the thalamus that codes the short-delay CR.

Our initial approach to identification of this circuit

This work was supported in part by a research grant from the National Science Foundation (BNS-8106648). We thank Jann Lincoln for assistance in histology. has been to map the entire brain stem in already trained animals by recording neural unit activity. In the course of this mapping, we discovered a clear pattern of increased unit activity in portions of the cerebellum that corresponds closely with the learned behavioral response. We then undertook two types of lesion studies, large ablations and more localized stereotaxic lesions, in well trained animals. All these results will be reported here.

It is important to emphasize the nature of the CR. Investigators typically record either extension of the $\mathrm{NM}$, which is a largely passive consequence of eyeball retraction (Cegavske, Thompson, Patterson, \& Gormezano, 1976), or closure of the external eyelid. However, with standard procedures for NM conditioning, both become conditioned simultaneously and synchronously, together with some degree of contraction of the periorbital facial musculature (Lavond, Judson, \& Thompson, Note 3; McCormick \& Thompson, Note 4). The major components are NM extension (eyeball retraction) and eyelid closure. Both were measured and/or observed in these experiments. When we refer to the CR below, we mean both the NM and eyelid. All effects reported here occur equally for both.

\section{METHOD}

Preliminary results from three experiments are reported here: (1) electrophysiological recording from the ipsilateral cerebellum of multiple-unit activity in well trained animals, (2) effects of large ablations (by aspiration) of the ipsilateral cerebellum in well trained animals, and (3) effects of localized electrolytic stereotaxic lesions in the ipsilateral cerebellum in well trained animals. Standard techniques were used for recording the NM and multiple-unit neural activity (Berger \& Thompson, 1978; Cegavske, Patterson, \& Thompson, 1979). We developed a chronic microdrive system that permits systematic mapping/ recording of multiple- or single-unit activity over a maximum 
extent of about $200 \mathrm{~mm}^{3}$ of brain tissue in a given animal. The microdrive system is implanted at least 5 days prior to training, using halothane anesthesia. After the animal is trained, a microelectrode is inserted, unit activity and NM are recorded (and eyelid response observed) for a block of eight paired trials, the electrode is advanced, recording is done again, and so on. In the present paper, we report results of multiple-unit recording in the lateral cerebellum.

Training conditions were identical for the electrophysiological study and the stereotaxic lesion study, and they have been described in detail elsewhere (Berger \& Thompson, 1978). The short-delay procedure was used: tone CS $(85 \mathrm{~dB}, 1 \mathrm{kHz}$, $350 \mathrm{msec}$ ), and corneal air-puff UCS given the last $100 \mathrm{msec}$ of the CS duration. The intertrial interval averaged $60 \mathrm{sec}$, and a tone-alone test trial was given every ninth trial. A total of 117 trials were given each day. Conditions were slightly different for the ablation studies (Kettner, Shannon, Nguyen, \& Thompson, 1980). The CS was a $36-\mathrm{dB}$ spectral-level white noise, and $75 \%$ of the trials were paired and $25 \%$ were CS alone in a random sequence with a 50 -sec intertrial interval, for a total of 120 trials per day. In the ablation study, all animals were trained to a criterion of eight CRs in nine successive trials and then given 1 full day of subsequent training, subjected to the ablation, allowed at least 5 days of recovery, and then given 4 full days of training. In the lesion study, lesion electrodes or micromanipulators were implanted 5 days prior to initial training, and the animals were trained as the ablation animals were. At the end of the day of overtraining, the animals were lightly anesthetized with halothane and the electrolytic lesion was made. The animals were allowed $24 \mathrm{~h}$ of recovery and then given 4 full days of retraining.

\section{RESULTS}

\section{Recordings}

A total of 15 animals have been studied to date. The electrophysiological recordings (multiple unit) show a pattern of increased unit activity during trial periods in the cerebellum. There is a tone-evoked onset-type response, an air-puff-evoked onset-type response, and a patterned increase in unit firing that forms a temporal model of the learned behavioral response. This last resembles the learning-induced response that develops in the hippocampus (Berger \& Thompson, 1978). However, unit activity in the hippocampus does not show the stimulus-evoked onset responses.

\section{Ablation}

Four animals have been run to date. All four learned to criterion in less than 2 days of original training. In all four animals, large ablation of the ipsilateral cerebellum completely abolished the conditioned response but had no effect at all on the unconditioned response. None of the four animals showed any clear signs of relearning the original conditioned response. Lesions in all four animals included at least the ansiform and paramedian lobes and most of the intermediate and dentate nuclei. As would be expected, these animals showed varying degrees of motor symptoms following ablation. The selective abolition of the CR by these cerebellar ablations is not due simply to nonspecific effects of the ablation procedure per se. In other studies, comparably large or larger ablations of other structures (e.g., posterior neocortex and varying amounts of the colliculi), using the same paradigm with 5 days of recovery, had no effect at all on the CR (McCormick, Kettner, \& Thompson, Note 5).

\section{Electrolytic Lesions}

A total of six animals have been run to date. Lesions localized to the dentate nucleus and vicinity produced complete abolition $(n=2)$ or severe impairment $(n=2)$ of the CR. Lesions that were dorsal and caudal to the dentate nucleus $(n=2)$ had no effect at all on the CR. In two of the animals in which the CR was abolished or severely impaired, there were no detectable motor symptoms.

\section{Training of Contralateral Eye}

At the end of the 4 days of postoperative training to the eye ipsilateral to the cerebellar lesion, three animals who showed not a single CR in postoperative training were selected, two with a large ablation and one with a localized stereotaxic lesion. They were then given training to the contralateral eye. All three learned in a few trials and maintained a robust and consistent CR. Training was again shifted back to the original (ipsilateral) eye, and none of the three animals showed any clear signs of conditioned responding.

\section{DISCUSSION}

The pattern of electrophysiological activity we found in the lateral cerebellum is what might be expected in a brain region that contains the "engram," namely, converging sensory information about the occurrence of the CS and the UCS and a neuronal representation of the learned behavioral response. Because the recordings are multiple unit, we do not yet know whether these various responses are generated by the same or different neurons. This will be determined with single-unit recording.

The ablation experiment indicates that the ipsilateral cerebellum is essential for the learned response. The stereotaxic lesion results suggest there is at least some degree of localization within the cerebellum (e.g., dentate nucleus and vicinity). The complete absence of any deficit in conditioned responding in animals with lesions dorsal and caudal to the dentate nucleus rules out possible nonspecific effects of at least the electrolytic lesion procedure. The fact that animals with large ablations or stereotaxic lesions that permanently abolished the CR ipsilateral to the lesion rapidly and easily learned the CR with the contralateral eye is decisive evidence against nonspecific lesion effects. The absence of motor symptoms in two of the electroly tic lesion animals with severe memory deficits argues that abolition of the $\mathrm{CR}$ is not simply a result of motor dysfunction.

We would like to suggest that the engram for short-delay classical conditioning of the NM and eyelid is localized within the ipsilateral cerebellum. Our results are consistent with this hypothesis. However, it is also possible that only a part of the engram, albeit an essential part, is in the cerebellum. In other current work, we have found complete abolition of the same CR with lesions in the ipsilateral pontine reticular formation (Lavond, McCormick, Clark, Holmes, \& Thompson, Note 6). However, the effective lesion site is close to the decussation of the brachium conjunctivum and may interrupt essential cerebellar connections. Alternatively, both structures may be a part of the essential learning-memory circuit.

Other possibilities exist. The most obvious is that the cerebellum is merely essential for the performance of the CR (i.e., the expression of the learned response). Even this is of great interest. The fact that cerebellar lesions have no effect on 
the UCR indicates that the circuitry essential for the learned response is separate from the circuitry involved in the unconditioned reflex response. Still another possibility is that the engram itself, the neural plasticity that codes the learned response, is localized elsewhere, and ipsilateral cerebellar damage produces abnormal or asymmetrical actions on this other region that prevent the expression of the CR. The fact that animals rapidly learned the $C R$ contralateral to the cerebellar lesion but showed no sign of retention or relearning of the ipsilateral CR argues against this interpretation, as do the electrophysiological data.

If an essential part of the neuronal plasticity that codes learning is in fact localized to the cerebellum, it seems probable that it is in the cerebellar cortex rather than the deep nuclei. It is difficult to imagine a more ideal structure in which to analyze the nature of the engram; the cerebellar cortex has a uniform and relatively simple organization and is very well characterized anatomically and physiologically (e.g., Eccles, Ito, \& Szentágothai, 1967; Llinás, 1969, 1974; Palay \& Chan-Palay, 1974; Shambes, Gibson, \& Welker, 1978). The cerebellum has long been suggested as a possible locus for the coding of learned motor responses (e.g., Eccles et al., 1967). We know of no reason to suppose that the cerebellum has a special role for such movements as NM extension and eyelid closure. Consequently, we argue that the present result may hold for all simple learned responses involving discrete, striated muscle movements. Although cerebellar lesions have been reported to impair a variety of skilled movements in animals (e.g., Brooks, 1975), to our knowledge the present experimental results are the first to show that damage to the ipsilateral cerebellum can selectively abolish a simple learned response. This result is nicely consistent with our earlier suggestion that the engram for simple learned responses is some form of a "motor plan" (Thompson et al., 1980).

\section{REFERENCE NOTES}

1. Weiss, D. J., Solomon, P. R., \& Thompson, R. F. The hippocampus appears necessary for trace conditioning. Paper presented at the annual meeting of the Psychonomic Society, St. Louis, Mo., November 1980.

2. Enser, D. Personal communication, July 26, 1976.

3. Lavond, D. G., Judson, S. M., \& Thompson, R. F. Simultaneous recordings from neurons of the accessory sixth and seventh cranial nuclei during classical conditioning of the nictitating membrane and eyelid responses. Manuscript in preparation, 1981.

4. McCormick, D. A., \& Thompson, R. F. Pattern of response of the facial musculature during classical conditioning of the nictitating membrane and eyelid response. Manuscript in preparation, 1981.

5. McCormick, D. A., Kettner, R. E., \& Thompson, R. F. Effects of bilateral ablation of the inferior colliculi on classical conditioning of the nictitating membrane and eyelid responses to an acoustic CS. Manuscript in preparation, 1981.

6. Lavond, D. G., McCormick, D. A., Clark, G. A., Holmes, D. T., \& Thompson, R. F. Effects of rostral ipsilateral pontine reticular lesions on retention of classical conditioning of the nicitating membrane and eyelid responses. Manuscript in preparation, 1981.

\section{REFERENCES}

Berger, T. W., \& Thompson, R. F. Neuronal plasticity in the limbic system during classical conditioning of the rabbit nictitating membrane response. I. The hippocampus. Brain Research, 1978, 145, 323-346.

Brooks, V. B. Roles of cerebellum and basal ganglia in initiation and control of movements. Canadian Journal of Neurological Sciences, 1975, 2, 265-277.

Cegavske, C. F., Patterson, M. M., \& Thompson, R. F. Neuronal unit activity in the abducens nucleus during classical conditioning of the nictitating membrane response in the rabbit, Oryctolagus cuniculus. Journal of Comparative and Physiological Psychology, 1979, 93, 595-609.

Cegavske, C. F., Thompson, R. F., Patterson, M. M., \& Gormezano, I. Mechanisms of efferent neuronal control of the reflex nictitating membrane response in the rabbit. Journal of Comparative and Physiological Psychology, 1976, 90, 411-423.

Eccles, J. C., Ito, M., \& Szentágothai, J. The cerebellum as a neuronal machine. Heidelberg: Springer-Verlag Berlin, 1967.

Ketrner, R. N., Shannon, R. V., Nguyen, T. M., \& Thompson, R. F. Simultaneous behavioral and neural (cochlear nucleus) measurement during signal detection in the rabbit. Perception \& Psychophysics, 1980, 28, 504-513.

Luinas, R. (Ed.). Neurobiology of cerebellar evolution and development: Proceedings of the First International Symposium of the Institute for Biochemical Research. Washington, D.C: American Medical Association, 1969.

Luinas, R. Eighteenth Bowditch lecture: Motor aspects of cerebellar control. Physiologist, 1974, 17, 19-46.

Megirian, D., \& Bures, J. Unilateral cortical spreading depression and conditioned eyeblink responses in the rabbit. Experimental Neurology, 1970, 27, 34-45.

Norman, R., Buchwald, J., \& Villablanca, J. Auditory discrimination of the classically conditioned eyeblink response in chronic decerebrate cats. Program Abstracts: 5th Annual Meeting of the Society for Neuroscience, 1975.

Palay, S. L., \& Chan-Palay, V. Cerebellar cortex: Cytology and organization. Berlin: Springer-Verlag, 1974.

Papsdorf, J. D., Longhan, D., \& Gormezano, I. Spreading depression: Effects of applying $\mathrm{KCl}$ to the dura of the rabbit on the conditioned nictitating membrane response. Psychonomic Science, 1965, 2, 125-126.

Shambes, G. M., Gibson, J. M., \& Welker, W. Fractured somatotopy in granule cell tactile areas of rat cerebellar hemispheres revealed by micromapping. Brain Behavior and Evolution, 1978, 15, 94-140.

Solomon, P. R., \& Moore, J. W. Latent inhibition and stimulus generalization of the classically conditioned nictitating membrane response in rabbits (Oryctolagus cuniculus) following dorsal hippocampal ablation. Journal of Comparative and Physiological Psychology, 1975, 89, 1192-1203.

Thompson, R. F., Berger, T. W., Berry, S. D., Hoehler, F. K., KettNer, R. E., \& Weiss, D. J. Hippocampal substrate of classical conditioning. Physiological Psychology, 1980, 8, 262-279.

(Received for publication August 12, 1981.) 